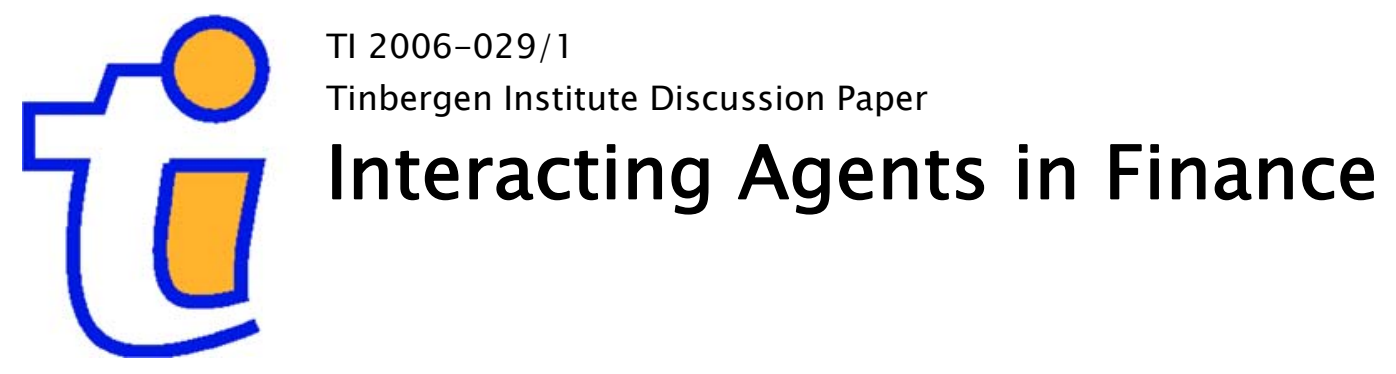

Cars Hommes

University of Amsterdam, and Tinbergen Institute. 


\section{Tinbergen Institute}

The Tinbergen Institute is the institute for economic research of the Erasmus Universiteit Rotterdam, Universiteit van Amsterdam, and Vrije Universiteit Amsterdam.

Tinbergen Institute Amsterdam

Roetersstraat 31

1018 WB Amsterdam

The Netherlands

Tel.: $\quad+31(0) 205513500$

Fax: $\quad+31(0) 205513555$

Tinbergen Institute Rotterdam

Burg. Oudlaan 50

3062 PA Rotterdam

The Netherlands

Tel.: $\quad+31(0) 104088900$

Fax: $\quad+31(0) 104089031$

Please send questions and/or remarks of nonscientific nature to driessen@tinbergen.nl.

Most TI discussion papers can be downloaded at http://www.tinbergen.nl. 


\title{
Interacting Agents in Finance
}

\author{
Cars Hommes* \\ CeNDEF, University of Amsterdam
}

January 2006

entry written for the New Palgrave Dictionary of Economics, Second Edition, edited by L. Blume and S. Durlauf, Palgrave Macmillan, forthcoming 2006.

\begin{abstract}
Interacting agents in finance represent a behavioral, agent-based approach in which financial markets are viewed as complex adaptive systems consisting of many boundedly rational agents interacting through simple heterogeneous investment strategies, constantly adapting their behavior in response to new information, strategy performance and through social interactions. An interacting agent system acts as a noise filter, transforming and amplifying purely random news about economic fundamentals into an aggregate market outcome exhibiting important stylized facts such as unpredictable asset prices and returns, excess volatility, temporary bubbles and sudden crashes, large and persistent trading volume, clustered volatility and long memory.
\end{abstract}

JEL classification: G1, E3, D01, D84.

acknowledgement. I would like to thank Mikhail Anufriev, Buz Brock and Yannis Ioannides for helpful comments on an earlier draft.

* address: CeNDEF, University of Amsterdam, Roetersstraat 11, NL-1018WB Amsterdam, the Netherlands. Phone number: + 3120525 4246, Fax numer: + 3120525 4349, email: c.h.hommes@uva.nl. 


\section{Interacting Agents in Finance}

Interacting agents in finance represent a new behavioral, agent-based approach in which financial markets are viewed as complex adaptive systems consisting of many boundedly rational, heterogeneous agents interacting through simple investment strategies, constantly learning from each other as new information becomes available and adapting their behavior accordingly over time. Simple interactions at the individual, micro level cause sophisticated structure and emergent phenomena at the aggregate, macro level. Recent surveys of this approach are Hommes (2006) and LeBaron (2006).

The traditional approach in finance is based on a representative, rational agent who makes optimal investment decisions and has rational expectations about future developments. Friedman (1953) made an early, strong argument in favor of rationality, arguing that "irrational" agents would lose money whereas rational agents would earn higher profits. This is essentially an evolutionary argument saying that irrational agents will be driven out of the market by rational agents. In a perfectly rational world, information is transmitted instantaneously, asset prices reflect economic fundamentals and asset allocations are efficient. In the traditional view, agents only interact through the price system.

In contrast, Keynes earlier stressed that prices of speculative assets are not only driven by market fundamentals, but that "market psychology" also plays an important role. Another early critique on perfect rationality is due to Simon (1957), who emphasized that agents are limited in their computing abilities and face information gathering costs. Therefore individual behavior is more accurately described by simple, suboptimal "rules of thumb". Along similar lines, Tversky and Kahneman (1974) in psychology argued that individual decision behavior under uncertainty can be better described by simple heuristics and biases. In the last decade the traditional view of financial markets has become challenged through developments in bounded rationality (e.g. Sargent, 1993), behavioral finance (e.g. Barberis and Thaler, 2003) and computational, agent-based modeling (e.g. Tesfatsion and Judd, 2006).

\section{Fundamentalists versus chartists}

Most interacting agents models in finance include two important classes of investors: fundamentalists and chartists. Fundamentalists base their investment decisions upon market fundamentals, such as interest rates, growth of the economy, company's earnings, etc. Fundamentalists expect the asset price to move towards its fundamental value and buy (sell) assets that are undervalued (overvalued). In contrast, chartists or technical analysts look for simple patterns, e.g. trends, in past prices and base their investment decisions upon extrapolation of these patterns. For a long time, technical analysis has been viewed as "irrational" and, according to the Friedman argument, chartists would be driven out of the market by rational investors. Frankel 
and Froot (1986) were among the first to emphasize the role of fundamentalists and chartists in real financial markets. Evidence from survey data on exchange rate expectations (e.g. Frankel and Froot, 1987, and Allen and Taylor, 1990) shows that at short time horizons (say up to 3 months) financial forecasters tend to use destabilizing, trend following forecasting rules, whereas at longer horizons (say 3-12 months or longer) they tend to use stabilizing, mean reverting, fundamental forecasts. Frankel and Froot (1986) argue that the interaction of chartists and fundamentalists amplified the strong rise and subsequent fall of the dollar exchange rate in the mid eighties.

Another simple interacting agent system with chartists and fundamentalists driven by herding behavior is due to Kirman $(1991,1993)$. This model was motivated by puzzling behavior of ants observed by entomologists. A colony of ants facing two identical food sources distributes asymmetrically, say $80 \%-20 \%$, over the two sources. Moreover, at some point in time the distribution suddenly reverses to $20 \%-80 \%$. Kirman (1993) proposed a simple stochastic model explaining ants' behavior and applied it to a financial market setting (Kirman, 1991). Agents can choose between two investment strategies, a fundamentalist or a chartist strategy, to invest in a risky asset. Two agents meet at random and with some interactionconversion probability one agent will adopt the view of the other. There is also a small self-conversion probability that the agent will change her view no matter what the other agent believes. It turns out that when the interaction-conversion probability is relatively high compared to the self-conversion probability, the distribution of agents is bimodal. The behavior of the agents is very persistent and the market tends to be dominated by one group for a long time, but then the majority of agents suddenly switches to the other view, etc.

But what about the Friedman argument? Will not "irrational" technical trading rules be driven out of the market by rational investment strategies? DeLong et al. (1990) presented one of the first models showing that this need not be the case. Their model contains two types of traders, noise traders, with erroneous stochastic beliefs, and rational traders who are perfectly rational and take into account the presence of noise traders. Noise traders create extra risk and risk averse rational traders are not willing to fully arbitrage away the mispricing. Noise traders bear more risk and can earn higher realized returns than rational traders, and therefore noise traders can survive in the long run. Lux (1995) presents a herding model with fundamentalists and chartists, whose behavior is driven by imitation and past realized returns leading to temporary bubbles and sudden crashes. Furthermore, Brock et al. (1992) showed empirically using 90 years of daily Dow Jones index data that technical trading rules can generate significant above normal returns. 


\section{Markets as complex adaptive systems}

Since the end of the eighties, multi-disciplinary research as done at the Santa Fe Institute (SFI) (e.g Anderson, Arrow and Pines, 1988) has stimulated a lot of work on interacting agents in economics and finance. Models of interacting particle systems in physics served as examples how local interaction at the micro level may explain structure, for example a phase transition, at the macro level. This has motivated economists to study the economy as an evolving complex system.

Arthur et al. (1997) consider the so-called SFI artificial stock market consisting of an ocean of different types of agents choosing among many simple investment strategies. Agents' investment decisions are affected by their expectations or beliefs about future asset prices. Beliefs affect realized prices, which in turn determine new beliefs, etc. Prices and beliefs about prices thus co-evolve over time, and agents continuously adapt their behavior as new observation become available, replacing less successful strategies by more successful ones. Are simple forecasting strategies irrational and will rational traders outperform technical traders in such an artificial market? In general not. The reason is that a speculative asset market is an expectations feedback system. Imagine a situation where an asset price is overvalued and the majority of traders remains optimistic expecting the rising trend to continue. Aggregate demand will increase and as a result the asset price will rise even further. Optimistic expectations thus become self-fulfilling and chartists will earn higher realized returns than fundamental traders who sold or shortened the asset because they expected a decline in its price. As long as optimistic traders dominate the market and reenforce the price rise, fundamentalists will lose money. Even when the fundamentalists may be right in the long run, there are "limits to arbitrage", e.g. due to short selling constraints, preventing them to hold their positions long enough against a prevailing optimistic view, as stressed by Shleifer and Vishny (1997).

\section{Emergent phenomena and stylized facts}

The interacting agents approach has been strongly motivated by a number of important stylized facts observed in many financial time series (e.g. Brock, 1997): (i) unpredictable asset prices and returns; (ii) large, persistent trading volume; (iii) excess volatility and persistent deviations from fundamental value, and (iv) clustered volatility and long memory. According to (i) asset prices are difficult to predict. New information is absorbed quickly in asset prices and there is "no easy free lunch", that is, arbitrage opportunities are difficult to find and exploit. The traditional rational, representative agent framework can explain (i), but has difficulty in explaining the other stylized facts (ii)-(iv). In particular, in a world with only rational, risk averse investors with asymmetric information there can be no trade, because no trader can benefit from superior information since other rational traders will anticipate that this agent must have superior information and therefore will not agree to trade (e.g. 
Fudenberg and Tirole (1991)). These no trade theorems are in sharp contrast to the huge daily trading volume observed in real financial markets, which suggests that there must be other types of heterogeneity such as differences in opinion about future movements. Stylized fact (iii) means that fluctuations in asset prices are much larger than fluctuations in underlying market fundamentals. This point has been emphasized e.g. by Shiller (1981). When markets are excessively volatile, prices can deviate from their fundamental values for a long time. Stylized fact (iv) means that price fluctuations are characterized by irregular switching between quiet, low volatility phases, with small price fluctuations, and turbulent phases of high volatility and large swings in asset prices. Interacting agent models have been able to explain these stylized facts simultaneously (e.g. LeBaron et al., 1999, Lux and Marchesi, 1999).

\section{Evolutionary selection of strategies}

Blume (1993) and Brock (1993) present a general probabilistic framework for strategy selection motivated by results from interacting particle systems in physics, see also Föllmer (1974). The probability of agents using strategy $h$ changes over time according to a random utility fitness measure of the general form

$$
U_{h t}=\pi_{h t}+S_{h t}+\epsilon_{h t}
$$

Here $\pi_{h t}$ represents private utility, for example given by (a weighted average of) realized profit, realized utility or forecasting performance. $S_{h t}$ represents social utility measuring herding behavior or social interactions as in Brock and Durlauf (2001a,b). For example, agents may behave as conformists, that is, they are more likely to follow strategies that are more popular among the population (global interaction) or among their neighbors (local interaction). Agents observe the performance of each strategy with some idiosyncratic errors, represented by $\epsilon_{h t}$.

A frequently used model for the probabilities or fractions of the different strategy types is the discrete choice or multinomial logit model

$$
n_{h t}=e^{\beta U_{h, t-1}} / Z_{t-1},
$$

where $Z_{t-1}=\sum_{j} e^{\beta U_{j, t-1}}$ is a normalization factor so that the fractions add up to one. When the errors $\epsilon_{h t}$ in (1) are independently and identically distributed according to a double exponential distribution, the probability of choosing strategy $h$ is exactly given by (2). The crucial feature of (2) is that the higher the fitness of trading strategy $h$ the more agents will select strategy $h$, and therefore it is essentially an evolutionary selection mechanism. Agents are boundedly rational and tend to follow strategies that have performed well in the (recent) past. The parameter $\beta$ is called the intensity of choice and is inversely related to the variance of the noise $\epsilon_{h t}$. It measures how sensitive agents are to selecting the optimal strategy. The extreme 
case $\beta=0$ corresponds to noise with infinite variance, so that differences in fitness cannot be observed and all fractions will be equal to $1 / H$, where $H$ is the number of strategies. The other extreme $\beta=+\infty$ corresponds to the case without noise, so that the deterministic part of the fitness is observed perfectly and in each period, all agents choose the optimal forecast. An increase in the intensity of choice $\beta$ represents an increase in the degree of rationality concerning strategy selection.

Brock and Hommes $(1997,1998)$ propose a simple, analytically tractable heterogeneous agent model to show how non-rational strategies can survive evolutionary selection. Brock and Hommes (1997) consider a market with an endogenous evolutionary selection of expectations rules described by the multi-nomial logit model (2), with fitness given by past realized profits. Agents choose between a set of different forecasting rules and tend to switch to forecasting strategies that have performed well in the recent past. When agents face information gathering costs, because sophisticated rational strategies are more costly to obtain, simple rule of thumb strategies can survive in this market. In Brock and Hommes (1998) this evolutionary selection of strategies is applied to a standard asset pricing model similar to, but much simpler than the SFI artificial stock market. Agents choose between fundamentalists'and chartists' investment strategies. When the sensitivity to differences in past performance of the strategies is high (i.e. the parameter $\beta$ is high), evolutionary selection of strategies destabilizes the system and leads to complicated, possibly chaotic asset price fluctuations around the benchmark rational expectations fundamental price. The fluctuations are characterized by an irregular switching between a quiet phase with asset prices close to the fundamental and a more turbulent phase with asset prices following (temporary) trends or bubbles. In contrast with Friedman's argument, chartists can survive in this evolutionary competition and may on average earn (short run) profits equal or even higher than (short run) profits of fundamentalists.

A common finding in these models is that more rationality, i.e. a larger intensity of choice, leads to instability. The intuition is that random choice leads to stability, because agents will be evenly distributed over the strategy space without systematic biases. In contrast, correlated choice may cause instability when e.g. many traders switch to a profitable trend following strategy. Another common finding is that when the social interaction effect is strong, multiple equilibria exist and it depends sensitively on the initial state to which of the many equilibria the market system will settle down (e.g. Brock and Durlauf 2001a,b).

\section{Summary and Future Perspective}

Although the approach in finance is relatively new interacting agent models have been able to explain important stylized facts simultaneously. An interacting agents system acts as a noise filter, transforming and amplifying purely random news about 
economic fundamentals into an aggregate market outcome exhibiting excess volatility, temporary bubbles and sudden crashes, large and persistent trading volume, clustered volatility and long memory. It should be emphasized that at the aggregate level these asset price fluctuations are highly irregular and unpredictable and there exists no easy free lunch and arbitrage will be very difficult and risky in such a market.

Much more theoretical work is needed in this area, for example, to find the 'simplest tractable model' explaining all important stylized facts. Speculative bubbles have been observed in laboratory experiments of Smith et al. (1988) and more recently in Hommes et al. (2005), showing that coordination on trend following rules can destabilize a laboratory experimental asset market. Another important topic for future research is estimation of interacting agent models on financial data. Boswijk et al. (2005) is one of the first attempts to estimation of an evolutionary model with fundamentalists versus trend following chartists using yearly S\&P 500 data, suggesting that trend following behavior amplified the strong rise in stock prices at the end of the nineties. In the next decade, more laboratory experiments and estimation of interacting agents models is needed to test the robustness and empirical relevance of the interacting agents approach.

\section{Cars Hommes}

See also: mathematics of networks, ergodicity and nonergodicity in economics, theory of social interactions, chaos, empirics of social interaction, network formation. Finance, corporate finance, finance: recent development, real estate finance. Bounded rationality, economic complexity. 


\section{References}

[1] Allen, H. and Taylor, M.P. (1990), Charts, noise and fundamentals in the London foreign exchange market, Economic Journal 100, 49-59.

[2] Anderson, P.W., Arrow, K.J. and Pines, D. (eds.), (1988), The Economy as an Evolving Complex System II Addison-Wesley, Reading, MA.

[3] Arthur, W.B., Holland, J.H., LeBaron, B., Palmer, R. and Taylor, P., (1997) Asset pricing under endogenous expectations in an artificial stock market, in Arthur, W., Durlauf, S., and Lane, D. (eds.) The economy as an evolving complex system II, Addison-Wesley.

[4] Barberis, N. and Thaler, R. (2003), A survey of behavioral finance, Handbook of the Economics of Finance, Edited by G.M. Constantinidis, M. Harris and R. Stulz, Elsevier.

[5] Blume, L., (1993) The statistical mechanics of strategic interaction, Games and Economic Behavior 5, 387-424.

[6] Boswijk, H.P., Hommes, C.H. and Manzan, S. (2005), Behavioral heterogeneity in stock prices, CeNDEF Working Paper WP-05-12, University of Amsterdam.

[7] Brock, W.A., (1993) Pathways to randomness in the economy: emergent nonlinearity and chaos in economics and finance, Estudios Económicos 8, 3-55.

[8] Brock, W.A., (1997), Asset Price Behavior in Complex Environments, in: Arthur, W.B., Durlauf, S.N., and Lane, D.A., eds., The Economy as an Evolving Complex System II, Addison-Wesley, Reading, MA, 385-423.

[9] Brock, W.A. and Durlauf, S.N. (2001a) Discrete Choice with Social Interactions, Review of Economic Studies 68, 235-260.

[10] Brock, W.A. and Durlauf, S.N. (2001b) Interactions-based Models, In: Heckman, J.J. and Leamer, E., Handbook of Econometrics Vol. 5, chapter 54, 32973380 .

[11] Brock, W.A., and Hommes, C.H., (1997) A rational route to randomness, Econometrica 65, 1059-1095.

[12] Brock, W.A., and Hommes, C.H., (1998), Heterogeneous beliefs and routes to chaos in a simple asset pricing model, Journal of Economic Dynamics and Control 22, 1235-1274.

[13] Brock, W.A., Lakonishok, J. and LeBaron, B., (1992) Simple technical trading rules and the stochastic properties of stock returns, Journal of Finance 47, 1731-64. 
[14] DeLong, J.B., Shleifer, A., Summers,L.H. and Waldmann, R.J., (1990) Noise trader risk in financial markets, Journal of Political Economy 98, 703-738.

[15] Föllmer, H. (1974) Random economies with many interacting agents, Journal of Mathematical Economics 1, 51-62.

[16] Frankel, J.A. and Froot, K.A., (1986) Understanding the US Dollar in the Eighties: The Expectations of Chartists and Fundamentalists, Economic Record, special issue, pp. 24-38.

[17] Frankel, J.A. and Froot, K.A., (1987) Using Survey Data to Test Standard Propositions regarding Exchange Rate Expectations, American Economic Review 77, 133-153.

[18] Friedman, M., (1953) The case of flexible exchange rates, In: Essays in positive economics, Univ. Chicago Press.

[19] Fudenberg, D. and Tirole, J., (1991), Game Theory, MIT Press, Cambridge.

[20] Hommes, C.H. (2006), Heterogeneous Agent Models in Economics and Finance, In: Handbook of Computational Economics, Volume 2: Agent-Based Computational Economics, chapter 23, Edited by L. Tesfatsion and K.L. Judd, Elsevier Science B.V., 2006, in press.

[21] Hommes, C.H., Sonnemans, J., Tuinstra, J., and van de Velden, H., (2005) Coordination of expectations in asset pricing experiments, Review of Financial Studies 12, 18, 955-980.

[22] Kirman, A., (1991) Epidemics of opinion and speculative bubbles in financial markets, In M. Taylor (ed.), Money and financial markets, Macmillan.

[23] Kirman, A., (1993) Ants, rationality and recruitment, Quarterly Journal of Economics 108, 137-156.

[24] LeBaron, B., (2006), Agent-based Computational Finance, In: Handbook of Computational Economics, Volume 2: Agent-Based Computational Economics, Edited by L. Tesfatsion and K.L. Judd, Elsevier Science B.V., 2006, to appear.

[25] LeBaron, B., Arthur, W.B. and Palmer, R. (1999) Time series properties of an artificial stock market, Journal of Economic Dynamics and Control 23, 14871516.

[26] Lux, T., (1995), Herd Behavior, Bubbles and Crashes, The Economic Journal $105,881-896$. 
[27] Lux, T. and Marchesi, M. (1999) Scaling and criticality in a stochastic multiagent model of a financial market, Nature Vol. 397, February 1999, 498-500.

[28] Sargent, T.J., (1993) Bounded rationality in macroeconomics, Clarendon Press, Oxford.

[29] Shiller, R.J., (1981) Do stock prices move too much to be justified by subsequent changes in dividends?, American Economic Review 71, 421-436.

[30] Shleifer, A and Vishny, R.W. (1997), The Limits of Arbitrage, Journal of Finance 52, 35-55.

[31] Simon, H.A. (1957), Models of man, Wiley, New York, NY.

[32] Smith, V., Suchanek, G.L. and Williams, A.W., (1988) Bubbles, crashes and endogenous expectations in experimental spot asset markets, Econometrica 56, 1119-51.

[33] Tesfatsion, L. and Judd, K.L., Eds. (2006), Handbook of Computational Economics, Volume 2: Agent-Based Computational Economics, Elsevier Science B.V., in press.

[34] Tversky, A. and Kahneman, D. (1974), Judgment under uncertainty: heuristics and biases, Science 185, 1124-1131. 